\title{
Bespreking en beoordeling van professioneel gedrag aan de Faculteit Geneeskunde te Maastricht
}

\author{
W.N.K.A. van Mook • S.J. van Luijk • M.J.G. Fey- \\ Schoenmakers • G.J.A.P.M. Oudhuis • M.T.H. Gulikers • \\ L.W. Schuwirth • C.P.M. van der Vleuten
}

Samenvatting De beoordeling van professioneel gedrag (PG) in het medisch onderwijs kan zich verheugen in een toenemende belangstelling. Om disfunctioneel gedrag om te kunnen buigen wordt in Maastricht veel tijd en energie gestoken in het geven van feedback en informatie. Daarnaast krijgt de summatieve kant van de PG beoordeling in jaar 1 en 2 van het curriculum de nodige aandacht. De summatieve en formatieve aspecten van de PG beoordeling spreken elkaar niet tegen, maar kunnen prima in één beoordelingssysteem verenigd worden. Hoewel aan verdere ontwikkeling en uitvoering van de formatieve aspecten, het longitudinale karakter en aan het scholen van studenten en staf wordt gewerkt, blijven deze aspecten een uitdaging voor de toekomst. Momenteel krijgen meer mannen dan vrouwen een onvoldoende oordeel PG, maar slechts een zeer kleine minderheid van de studenten vertoont dusdanig onprofessioneel gedrag dat verdere begeleiding noodzakelijk is. De redenen voor de onvoldoende oordelen zijn met name terug te voeren op de binnen PG vallende categorieën 'omgaan met werk' en 'omgaan met anderen'.

\footnotetext{
W.N.K.A. van Mook ( $\square)$

Drs. W.N.K.A. van Mook is internist-intensivist, voorzitter commissie Professioneel Gedrag, capaciteitsgroep Onderwijsontwikkeling en onderwijsresearch, Faculteit der Geneeskunde, Universiteit Maastricht.Correpondentieadres: Drs. W.N.K.A. van Mook, afdeling Intensive Care en Interne Geneeskunde, Academisch ziekenhuis Maastricht, P. Debeyelaan 25, 6229 HX Maastricht, tel.: 043- 3876385; e-mail wvm@sint.azm.nlBelangenconflict: geen gemeld.Financiële ondersteuning: geen gemeld.
}

\section{Inleiding}

De toegenomen aandacht voor het beoordelen en bespreken van professioneel gedrag (PG) wordt onder andere veroozaakt door maatschappelijke veranderingen, waaronder de toename van complexiteit van zorg, de hogere eisen die gesteld worden aan en door collega's en patiënten (organisaties), de noodzaak tot (re-)certificering, de kwaliteitsverbetering en de bewaking van de kosten en patiëntenveiligheid. ${ }^{1-2}$ Recent is aangetoond dat disciplinaire maatregelen door beroepsorganisaties tegen artsen inderdaad sterk geassocieerd zijn met onprofessioneel gedrag tijdens hun opleiding geneeskunde. Het sterkste verband werd gevonden bij studenten die omschreven werden als onverantwoordelijk, en bij wie het niet lukte het onprofessionele gedrag te verbeteren. ${ }^{3}$ De opleidingsinstituten geneeskunde hebben dus een belangrijke taak bij het bewaken van de professionele kwaliteit van afstuderende studenten die een rol als medicus binnen de maatschappij gaan vervullen.

Ook maatschappelijke en medische organisaties benadrukken het belang van het onderwijs in en de beoordeling van het professioneel gedrag van studenten en afgestudeerden. Zo houdt de voorzitter van de Association of Medical Colleges in een recent artikel een warm pleidooi voor het onderwijs in en het evalueren van PG in de Verenigde Staten. ${ }^{4}$ En in Nederland zijn in het Raamplan eindtermen geformuleerd ten aanzien van de domeinen kennis, vaardigheden en professioneel gedrag. ${ }^{5}$ Het Discipline Overlegorgaan Medische Wetenschappen (waarin de medische faculteiten op bestuurlijk niveau samenwerken binnen de Vereniging van Samenwerkende Nederlandse Universiteiten) heeft een nationale werkgroep ingesteld, waarin vertegenwoordigers van de faculteiten geneeskunde, tandheelkunde en diergeneeskunde 
zitting hebben. Deze projectgroep Consilium Abeundi presen- teerde in 2002 een rapport dat wat betreft PG voor de faculteiten als leidraad kan dienen. In dit rapport zijn naast geformuleerde richtlijnen en aanbevelingen ten aanzien van onderwijs, toetsing en begeleiding van studenten met onprofessioneel gedrag ook aanbevelingen opgenomen op grond van juridische problematiek en hieruit resulterende uitspraken. ${ }^{6}$ Binnen deze aanbevelingen en richtlijnen is vanzelfsprekend ruimte voor eigen visie en invulling. Het bespreken en beoordelen van PG aan de medische faculteiten gebeurt dan ook op verschillende manieren.

Binnen de discussie over het professioneel gedrag ontstaat nogal eens verwarring over de doelstellingen van het bespreken en beoordelen. Soms wordt de nadruk gelegd op het summatieve, selectieve aspect, met name om de 'horken' eruit te filteren en soms op het formatieve, vormende aspect met als doel het professioneel gedrag van alle studenten te verbeteren. Het lijkt vaak alsof die twee aspecten niet met elkaar verenigbaar zijn. In dit artikel willen we aan de hand van een casusbeschrijving, de PG beoordeling in Maastricht, laten zien dat beide aspecten juist goed naast elkaar kunnen bestaan, en elkaar niet per definitie uitsluiten.

\section{Korte toelichting op het huidige Maastrichtse curriculum}

Om het bespreken en beoordelen van professioneel gedrag goed te kunnen plaatsen is enig inzicht in het huidige Maastrichtse curriculum gewenst. Maastricht kent een bachelor-masterstructuur $(3+3$ jaar $)$. In de eerste twee jaren ligt het accent op het verwerven van kennis, waarbij gebruik wordt gemaakt van papieren en simulatiepatiënten. In het derde jaar en verder functioneren echte patiënten als startpunt voor het leren. In jaar 1 en 2 is het bespreken en beoordelen van professioneel gedrag vooral gericht op het professioneel gedrag in de student-docent relatie; in de latere jaren verschuift het accent van de PG beoordeling naar de student-patiënt relatie.

\section{Regels, richtlijnen en eindverantwoordelijkheid}

Vanaf het studiejaar 1995/1996 is in het Onderwijs- en Examen Reglement (OER) van de faculteit geneeskunde te Maastricht opgenomen dat bij ieder examenbesluit een PG beoordeling plaatsvindt. Een hiertoe ingestelde commissie Professioneel Gedrag is verantwoordelijk voor het bespreken en beoordelen van PG in jaar 1 en 2 . Sinds $1999 / 2000$ is een gevalideerd beoordelingsformulier in gebruik, dat in 2001 haar definitieve vorm bereikte (zie bijlage H, Eindrapport Projectteam Consilium Abeundi,${ }^{6}$ of opvraagbaar bij eerste auteur). Het formulier is gebaseerd op de door het Consilium Abeundi geformuleerde categorieën 'omgaan met werk en taken', 'omgaan met anderen' en 'omgaan met eigen functioneren'. Dit beoordelingsformulier dient in jaar 1 en 2 als leidraad en onderlegger bij het bespreken en beoordelen van PG tijdens alle reguliere onderwijsmomenten waarbij sprake is van een intensief contact tussen docent en studenten. Een voorbeeld hiervan is een onderwijsgroep, waarin een docent gedurende zes weken met dezelfde groep studenten aan een serie problemen werkt. Daarnaast is het mogelijk om binnen de PG beoordeling bijzonder positieve of negatieve gebeurtenissen onder de aandacht te brengen en te documenteren.

Op grond van de PG beoordelingen in de loop van het jaar, aangevuld met eventueel binnengekomen incidentele meldingen, komt de commissie PG tot een eindoordeel PG. De commissie PG bespreekt alle PG beoordelingen en correspondeert met de Examencommissie (EC) over incidentele meldingen, onvoldoende oordelen en het eindoordeel. De Commissie PG is in jaar 1 en 2 belast met het examineren en draagt daarmee ook de eindverantwoordelijkheid wat betreft de PG beoordelingen. Ook in de overige jaren wordt PG vanzelfsprekend besproken en beoordeeld, maar de eindverantwoordelijkheid voor de PG beoordeling in deze jaren ligt vooralsnog bij de EC. Dit onderscheid is initieel gemaakt om vooral in de eerste twee jaren intensieve zorg te kunnen bieden rondom professioneel gedrag.

\section{Het onderwijs in professioneel gedrag in jaar 1 tot en met 3}

Op dit moment is in de eerste drie jaren het onderwijs in facetten van professioneel gedrag ondergebracht in het zogenaamde MPO (Medisch Praktisch Onderwijs)- programma. Aspecten als zelfreflectie, sterkte-zwakte analyse, bewustwording, intervisie, attitude, professioneel gedrag, feedback, gespreksvaardigheden en communicatie komen hierin uitgebreid aan bod. In kleine groepen bespreken de studenten hun praktijkervaringen en de contacten met de simulatiepatiënten; de longitudinale follow-up geschiedt door ervaren, hiervoor geschoolde docenten. Naast onderwijs in aspecten van professioneel gedrag wordt in het MPOprogramma ook het professioneel gedrag beoordeeld. Vanwege de langdurige groepsrelatie zijn de uitkomsten van de evaluatie van het MPO-programma, zowel van de kant van docenten als studenten, ronduit goed te noemen. Naast dit reeds jaren lopende programma zal m.i.v. 2007/2008 ook in het eerste jaar in een plenair college informatie worden verstrekt over de betekenis en achtergronden van het 
bespreken en beoordelen van professioneel gedrag en de plaats ervan in het toetssysteem.

\section{Informatieverstrekking en praktijk van het bespreken van professioneel gedrag}

Nieuwe docenten krijgen via de commissie PG schriftelijke en mondelinge informatie en praktische tips voor het beoordelen en bespreken van professioneel gedrag. Tijdens de door de commissie georganiseerde jaarlijkse intervisie-bijeenkomst en een zevental vragenuurtjes kunnen docenten vragen stellen en eventuele problemen bespreken. Voor de intervisiebijeenkomst melden zich meestal een tiental tutoren aan; bij de vragenuurtjes wordt dit aantal meestal overschreden. Voor studenten en docenten is schriftelijke en web-based informatie beschikbaar. De blokcoördinatoren worden per e-mail gevraagd de voor de PG bespreking noodzakelijke tijd in de roosters te reserveren. Professioneel gedrag lijkt steeds meer al volwaardig onderdeel van het reguliere onderwijs gezien te worden, waarvoor ook de tutoren tijd vrijmaken. Het fenomeen dat het bespreken en beoordelen van professioneel gedrag 'tussen de soep en de aardappelen' moest gebeuren wordt steeds minder waargenomen.

In ieder onderwijsblok/cursus zijn er drie momenten waarop aandacht aan PG besteed wordt: bij aanvang, tussentijds en op het eind. De bespreking halverwege het onderwijsblok vergt de meeste tijd, ongeveer een uur voor 9-11 studenten. De student geeft tijdens de tussentijdse bespreking zelf aan welke facetten van zijn functioneren aandacht behoeven, en welke hij adequaat vindt; hierna volgt de feedback door medestudenten en tutor. Voorafgaand aan de bespreking ligt de nadruk dus op zelfreflectie en bewustwording van eigen functioneren; tijdens de bespreking staat de feedback naar aanleiding van deze kwalitatieve oordelen centraal. Tevens wordt een tussentijds summatief oordeel gegeven.

Tijdens de eindbespreking wordt naast de bekende en eventueel nieuwe kwalitatieve oordelen en plan van aanpak ook een definitief summatief oordeel (onvoldoende, voldoende of 'geen oordeel') gegeven. Het judicium 'geen oordeel' is aan de orde wanneer een student zo vaak (of altijd) afwezig is geweest dat er geen betrouwbaar en valide oordeel gegeven kan worden. In geval van gerede twijfel (tussen onvoldoende en voldoende) geeft de commissie er de voorkeur aan te kiezen voor een onvoldoende in plaats van voor de gebruikelijke 'genade-zes'. Het blijkt namelijk dat als de commentaren die niet direct als echt positief of negatief te interpreteren zijn worden gecorreleerd aan een beoordeling in de vorm van een (school)cijfer, deze eigenlijk allemaal negatief bedoeld zijn. ${ }^{7}$ De beoordeling op het einde van het blok wordt mondeling en schriftelijk beargumenteerd, en de student wordt verzocht 'voor kennisgeving' te tekenen. Dit betekent niet noodzakelijkerwijs dat de student ook akkoord is met het oordeel.

Met ingang van studiejaar 2005/2006 is de procedure voor het omgaan met en afhandelen van onvoldoende oordelen en 'geen oordeel' verder ontwikkeld tot de huidige situatie die hieronder wordt toegelicht.

\section{Het vormen van een oordeel PG gedurende het jaar}

De commissie PG inventariseert per afgeronde onderwijsactiviteit de beoordelingen PG. Alle studenten met een onvoldoende PG beoordeling krijgen het verzoek schriftelijk te reageren; in het kader van hoor en wederhoor wordt ook de docenten gevraagd hun mening te geven. Vervolgens ontvangen de studenten een uitnodiging voor een gesprek met de commissie waarin ze hun standpunten mondeling kunnen toelichten. Dezelfde procedure wordt gevolgd voor studenten die drie keer of meer 'geen oordeel' hebben gekregen; dit zou een vroege aanwijzing kunnen zijn voor structurele problemen, zeker als de student meerdere 'geen oordelen' achter elkaar heeft gekregen. Reageert een student niet op verzoeken per e-mail en op een (aangetekende) uitnodiging op gesprek te komen, dan wordt dit opgevat als onprofessioneel gedrag, hetgeen resulteert in een onvoldoende eindejaarsoordeel.

Voorafgaand aan de gesprekken bespreekt de commissie de onvoldoendes en de 'geen oordeel' meldingen met de studieadviseurs, met als doel te inventariseren welke studenten reeds bekend zijn en adequate adviezen, begeleiding en counselling te faciliteren. Het blijkt dat bij structurele problemen, naast lacunes in professioneel gedrag, ook vaak een of meerdere aspecten van kennis en vaardigheden onvoldoende zijn. Tijdens het gesprek krijgt de student uitleg over de achtergronden van het bespreken en beoordelen van PG. Daarna komt de reden van de onvoldoende beoordeling of 'geen oordeel' aan de orde, waarbij zowel student als commissie PG hun mening kunnen geven. De commissie geeft de student adviezen, en als dit niet afdoende wordt geacht wordt de student verwezen naar studiebegeleider, studentpsycholoog, mentor, loopbaanadviseur enz. Desgewenst kan verwijzing naar instanties buiten de faculteit, zoals huisarts, geestelijk verzorgende of psychiater, plaatsvinden. Tevens besluit de commissie of de eenmalige onvoldoende beoordeling zou moeten leiden tot een onvoldoende eindejaarsoordeel. Is dit het geval dan dient dit advies aan de EC te worden voorgelegd. Student, docent, en zo nodig mentor, ontvangen een afschrift van deze correspondentie. Een onvoldoende 
PG beoordeling moet voor de student altijd aanleiding zijn dit met zijn mentor te bespreken. De student is verplicht alle PG beoordelingen in zijn portfolio (indien portfolio in de opleidingsfase gebruikt wordt) op te nemen, zodat de mentor kennis kan nemen van voortgang en aandachtspunten wat betreft professioneel gedrag.

Naast de reguliere PG beoordelingen ontvangt de commissie incidentele meldingen van onvoldoende PG, die soms van ernstiger aard zijn dan de onvoldoendes tijdens de reguliere beoordelingsmomenten. Denk hierbij aan meldingen door bijvoorbeeld practicumbegeleiders, medewerkers van de informatiebalie voor studenten, en door keuzeblokdocenten; feitelijk al degenen die frequente contacten met studenten hebben buiten de reguliere onderwijsmomenten om. Er kan bijvoorbeeld sprake zijn van seksuele intimidatie, verbale agressie of bedreiging met soms als resultaat een (dreigende) verwijdering uit het onderwijs. Hiervoor hanteert de commissie dezelfde procedure als hierboven beschreven, met dien verstande dat dreigende verwijdering uit het onderwijs een onderwijskundige noodsituatie is en haast geboden is wat betreft de afhandeling. Het algoritme in figuur 1 geeft inzicht in de PG beoordelingsprocedure na ieder regulier onderwijsmoment in jaar 1 en 2.

\section{Het vormen van een oordeel PG aan het einde van het studiejaar}

Het eindoordeel van de commissie PG komt tot stand door een kwalitatieve afweging van alle voorliggende informatie (alle reguliere en eventueel incidentele PG beoordelingen). Het algoritmisch advies (de 'rekenregel'), waarbij op grond van het aantal maal voldoende, onvoldoende en 'geen oordeel' het eindoordeel wordt bepaald, is al enige jaren verlaten omdat hiermee voorbij werd gegaan aan een aantal belangrijke aspecten. Ten eerste het moment waarop de onvoldoendes zich voordoen. Begint het jaar goed maar wordt het jaar afgesloten met een aantal onvoldoendes dan kunnen deze onvoldoendes een andere betekenis hebben dan wanneer deze zich in het begin van het jaar voordeden, maar de beoordelingen nu allemaal 'voldoende' als oordeel hebben.

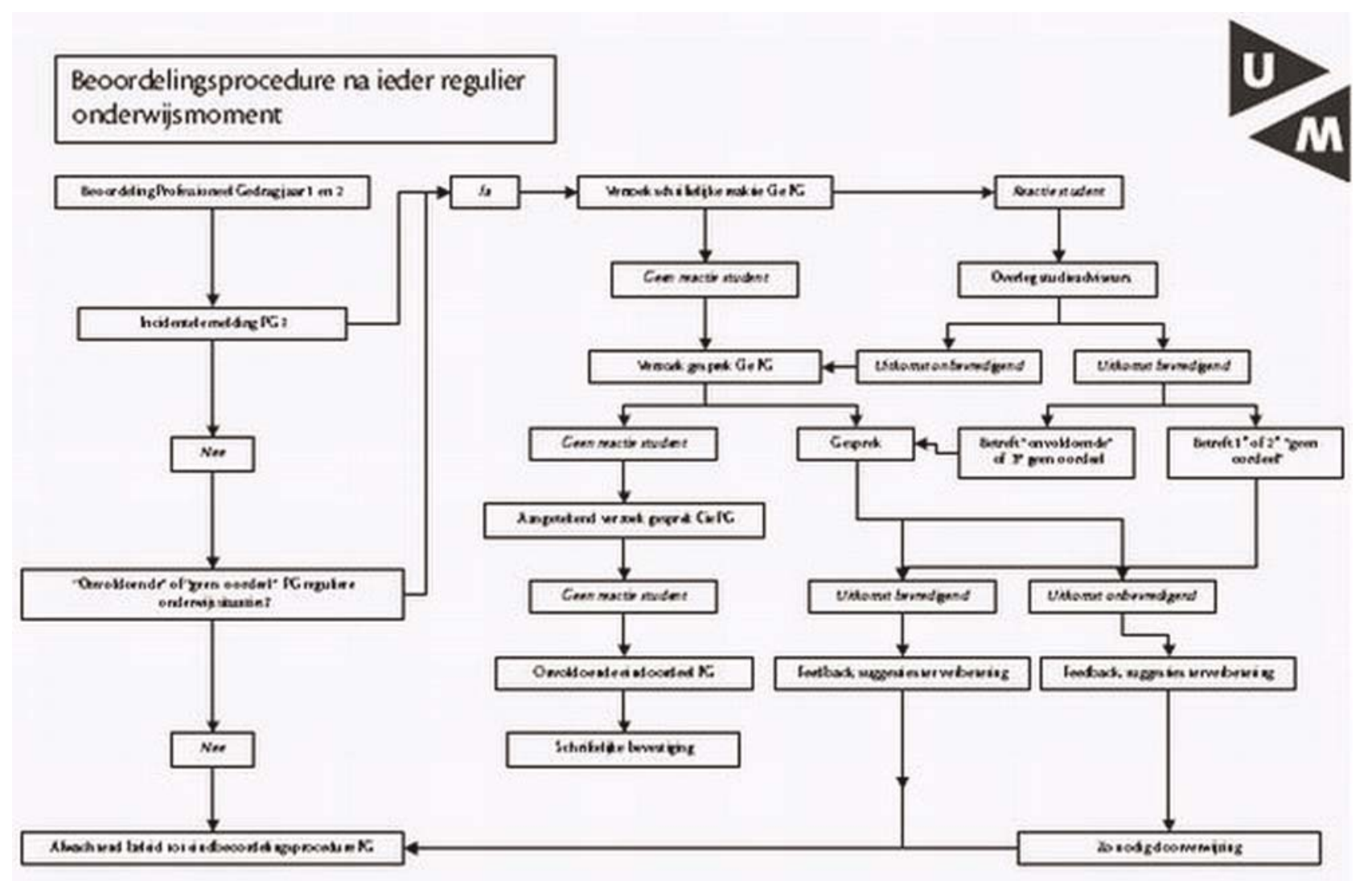

Figuur 1 Algoritme betreffende de afhandeling van de beoordeling professioneel gedrag aan de FaculteitGeneeskunde, Universiteit Maastricht, na ieder regulier onderwijsmoment. 
Professioneel gedrag is per slot van rekening iets wat zich longitudinaal ontwikkelt, en wat kan verbeteren. Ten tweede heeft niet elke PG beoordeling hetzelfde gewicht: de commissie hecht relatief veel waarde aan beoordelingen tijdens de onderwijsmomenten waarop de student longitudinaal over een langere periode is gevolgd en beoordeeld, zoals bijvoorbeeld de MPO-bijeenkomsten. Ten derde houdt een rekenregel ook bij onvoldoende beoordelingen binnen gelijkwaardige onderwijsmomenten geen rekening met verschillen in kwaliteit van het oordeel. Bijvoorbeeld: een onvoldoende oordeel PG voor het bij herhaling te laat verschijnen op onderwijsactiviteiten heeft een ander gewicht, en behoeft andere maatregelen c.q. begeleiding, dan een onvoldoende voor het telefonisch uiten van bedreigingen aan het adres van een begeleider. Ten vierde houdt een rekenregel geen rekening met de mogelijkheid van incidentele meldingen PG, en de aard ervan. Bij een onvoldoende eindoordeel of onmogelijkheid tot het geven van een oordeel ('geen oordeel') kan de commissie PG beslissen de studiepunten niet toe te kennen. De EC neemt dit besluit vervolgens over. Bij onvoldoende studiepunten is het niet mogelijk in het daaropvolgende studiejaar te beginnen. Bij voldoende studiepunten kan de student wel in het volgende studiejaar beginnen, maar dient de deficiëntie voor professioneel gedrag dat jaar weggewerkt te worden met een voldoende PG beoordeling.

Het algoritme in figuur 2 geeft inzicht in de beoordelingsprocedure PG op het einde van jaar 1 en 2.

\section{Eerste ervaringen met de huidige structuur}

Hieronder volgt een overzicht van de in 2005/2006 opgedane ervaringen met de bovengeschetste structuur in jaar 1 en 2.

Van de 359 eerstejaars studenten kregen 10 eerstejaars studenten een onvoldoende en ontvingen 54 studenten 'geen oordeel' omdat ze tijdens reguliere onderwijsactiviteiten te veel of niet aanwezig waren geweest. Meer mannen dan vrouwen ontvingen in jaar 1 een onvoldoende PG: $\mathrm{n}=8$ (op een totaal van $131,6 \%$ ) respectievelijk $\mathrm{n}=2$ (op een totaal van $228,0.9 \%$ ). Van de groep van $64(54+10)$ studenten kregen, na het bezien

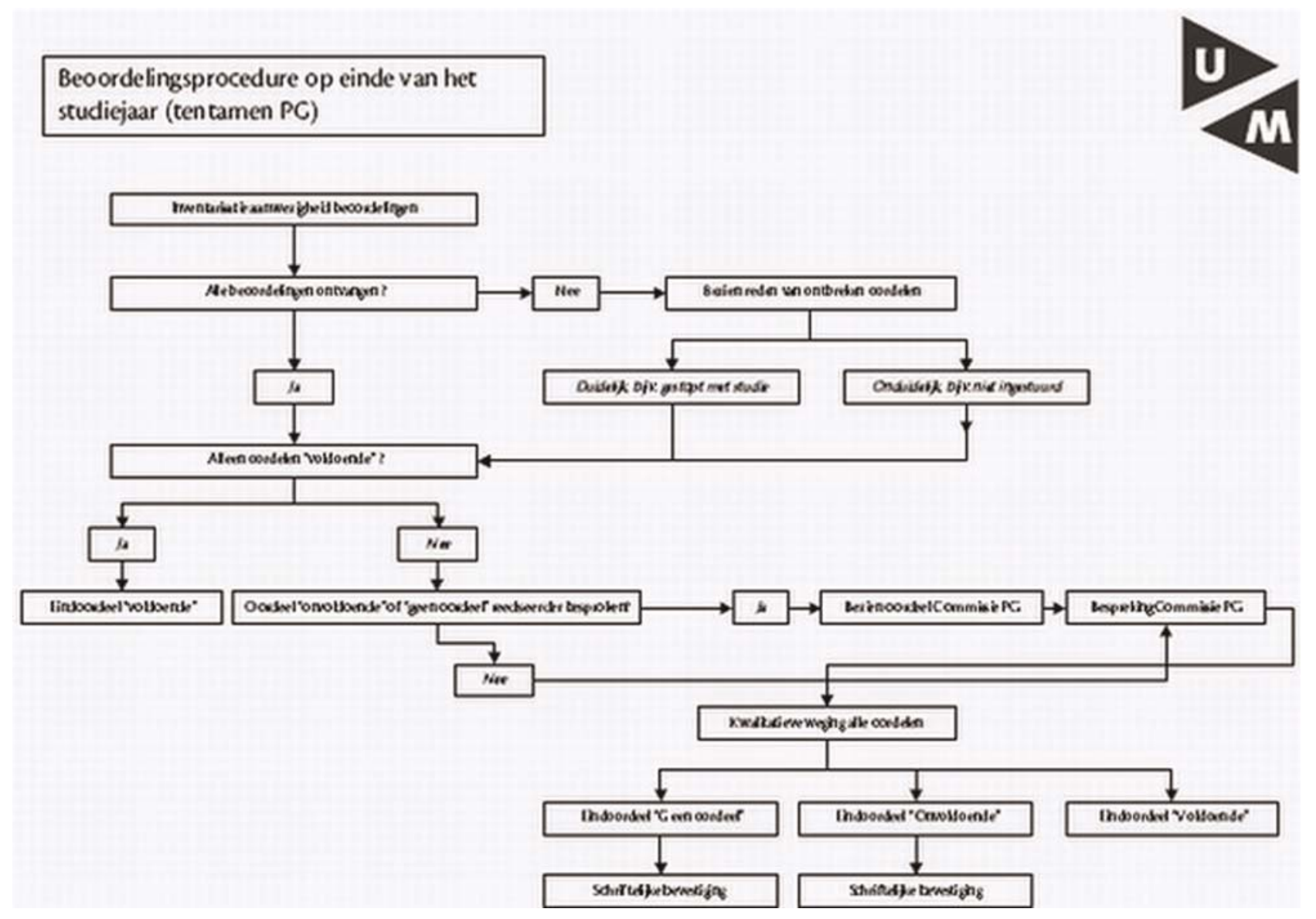

Figuur 2 Algoritme betreffende de bepaling van de eindbeoordeling professioneel gedrag aan de Faculteit Geneeskunde, Universiteit Maastricht, na het doorlopen van alle reguliere onderwijsmomenten op het einde van het jaar. 
van de eventuele schriftelijke reactie, 18 studenten een uitnodiging voor een gesprek met de commissie PG. 14 studenten gaven hieraan gehoor en ontvingen allemaal uitleg over de reden van een PG beoordeling, alsmede feedback op hun functioneren. Uiteindelijk werd op grond van de onvoldoendes en 'geen oordeel' reguliere jaar 1 oordelen (in totaal dus $54+10$ ) per direct besloten tot het geven van één onvoldoende eindoordeel. Naast de 10 reguliere onvoldoende PG oordelen ontving de commissie over twee studenten in totaal drie incidentele meldingen onvoldoende PG. Voor beide studenten resulteerde dit in een onvoldoende eindoordeel. De redenen voor de onvoldoende oordelen waren met name terug te voeren op de PG categorieën 'omgaan met werk' en 'omgaan met anderen'.

In totaal ontvingen in het kader van de PG beoordeling in jaar 1 van de 338 studenten drie studenten een onvoldoende eindoordeel, en werden vier studenten doorverwezen naar de studieadviseurs. Voor het daadwerkelijk maken van een afspraak zijn de studenten primair zelf verantwoordelijk; verschijnen ze niet op een afspraak dan worden ze door de studieadviseurs opnieuw benaderd.

In hetzelfde curriculumjaar namen 367 tweedejaars studenten deel. 24 studenten kregen een onvoldoende, en 56 studenten 'geen oordeel' tijdens reguliere onderwijsmomenten. Van deze 80 studenten werden, na bezien van eventuele schriftelijke reacties, met 28 studenten gesprekken gevoerd. Ook in jaar 2 ontvingen meer mannen dan vrouwen een onvoldoende oordeel PG $(n=18$, op een totaal van $149,12 \%$, respectievelijk $\mathrm{n}=6$, op een totaal van $218,3 \%$ ). Deze onvoldoende PG beoordeling resulteerde bij vier studenten uit jaar 2 in een onvoldoende eindoordeel. Studenten die op gesprek kwamen ontvingen allemaal uitleg over de reden van de PG beoordeling, alsmede feedback op hun functioneren. Daarnaast ontving de commissie drie incidentele meldingen onvoldoende PG. Voor twee studenten resulteerde dit in een onvoldoende eindoordeel. Ook in jaar 2 zijn de redenen voor de onvoldoende oordelen met name terug te voeren op de PG categorieën 'omgaan met werk' en 'omgaan met anderen'.

In totaal zijn er onder 351 studenten zes onvoldoende eindoordelen gegeven, en zijn vijf studenten doorverwezen naar de studieadviseurs. Een Consilium Abeundi is in 2005/2006 in jaar 1 en 2 niet gegeven. De redenen voor de onvoldoende PG beoordelingen betroffen meestal (te frequente) ongeoorloofde afwezigheid zonder communicatie hieromtrent, te weinig interactie tijdens het onderwijsmoment, ongeïnteresseerde houding/nonchalance, onvoldoende voorbereiding, en het bij herhaling niet reageren op verzoeken tot correspondentie van docentzijde.

\section{Conclusie en toekomstige ontwikkelingen}

Het summatieve en formatieve aspect van professioneel gedrag zijn in een beoordelingssysteem goed met elkaar verenigbaar. De stelling "Toetsen stuurt leren", of "They do not respect what you do not inspect" impliceert dat formatieve en summatieve aspecten in ieder toetssysteem naast elkaar kunnen voorkomen. Het formatieve en het summatieve aspect van het beoordelen van PG gaan zeker in het MPO-programma hand in hand, maar ook daarbuiten krijgen alle studenten in de onderwijsgroepen feedback op hun functioneren, ook als hun professioneel gedrag voldoende beoordeeld wordt. Studenten met een 'geen oordeel' of een onvoldoende krijgen daarnaast tevens in rechtstreeks contact met de commissie PG feedback op hun handelen.

In de toekomst zal de aandacht aan de Universiteit Maastricht uitgaan naar het verder verbeteren van de informatieverstrekking aan studenten en stafleden. Hoewel er recht wordt gedaan aan het summatieve karakter van PG beoordeling wat betreft aandacht, beoordelingsstructuur en dossiervorming, ontbreekt de mogelijkheid tot het instellen van een bindend studieadvies. De aandacht voor PG zal dit onderwerp opnieuw op de agenda plaatsen. Het formatieve aspect heeft voldoende aandacht gekregen bij nieuwe tutoren, doch kan bij ervaren tutoren nog sterk verbeterd worden, met name wat betreft het geven en documenteren van kwalitatieve en beschrijvende informatie. Het geven van instructie en uitleg aan deze groep is inmiddels geïnitieerd. Het verder versterken van het longitudinale karakter van PG, bijvoorbeeld door middel van implementatie van bespreeken toetsmomenten met een blokoverstijgend karakter (bijvoorbeeld bijeenkomsten in kleine groepen waarin wordt gereflecteerd op tevoren bepaalde schriftelijke casus, of videovignetten), behoort tot de mogelijkheden. ${ }^{8}$ Daarnaast lijkt het wenselijk de beoordeling van PG in alle opleidingssituaties en -jaren door dezelfde commissie te laten verrichten. Dit zal gefaseerd worden geëffectueerd. Inmiddels is de verantwoordelijkheid van de commissie PG uitgebreid tot de hele bachelorfase (jaar 1 tot en met 3).

Een lastiger te beïnvloeden aspect is het leren in het 'verborgen' curriculum. Aandacht voor de functie van rolmodellen in de klinische praktijk is nodig, evenals instructie en uitleg aan klinische docenten, zeker gezien de door het CCMS geadopteerde CanMeds opleidingscompenties voor medische specialisten in opleiding, waarin PG is opgenomen. ${ }^{9}$

\section{Summary}

Evaluation and assessment of professional behaviour (PB) is receiving increasing attention in the educational literature as well as educational practice. Although the focus tends to be on the 
summative aspects, it seems perfectly feasible to combine formative and summative assessment in one procedure. At Maastricht University efforts are made to provide information and feedback regarding professional behaviour to staff and students in order to strengthen formative assessment of professional behaviour. In the first two years of the curriculum ample attention is paid to the summative aspects of professional behaviour too. Challenges for the future are: further development and implementation of these aspects as well as longitudinal assessment and training of students and staff, and promoting a positive educational climate in the clinical setting by stimulating role modelling. Currently, there are more male students than female students who display inappropriate professional behaviour but it is only a small minority of students who display severe dysfunctional behaviour requiring long-term counselling and guidance. Most of the reasons for this inappropriate behaviour are related to the categories 'dealing with work' and 'dealing with others'. (Mook WNKA van, Luijk SJ van, Fey-Schoenmakers MJG, Oudhuis GJAPM, Gulikers MTH, Schuwirth LW, Vleuten CPM van der. Evaluation and assessment of professional behaviour at the Faculty of Health, Medicine and Life Sciences, Maastricht. Dutch Journal of Medical Education 20007;26(5): 237-246).

\section{Literatuur}

Irvine D. The performance of doctors. I: Professionalism and self regulation in a changing world. BMJ 1997;314(7093):1540-2.
Castellani B, Wear D. Physician views on practicing professionalism in the corporate age. Qual Health Res 2000;10(4):490-506.

Papadakis MA, Teherani A, Banach MA, et al. Disciplinary action by medical boards and prior behavior in medical school. $\mathrm{N}$ Engl J Med 2005;353(25):2673-82.

Cohen JJ. Professionalism in medical education, an American perspective: from evidence to accountability. Med Educ 2006;40(7):607-17.

Metz JCM, Verbeek-Weel AMM, Huisjes HJ. Raamplan 2001 Artsopleiding. Bijgestelde eindtermen van de artsopleiding. Nijmegen: Mediagroep; 2001.

Projectteam Consilium Abeundi. Professioneel gedrag: Onderwijs, toetsing, begeleiding en regelgeving. Eindrapport van het Projectteam Consilium Abeundi, ingesteld door DMW (VSNU), Urecht: 2002.

Frohna A, Stern D, LaSala KB, Nelson J. The nature of qualitative comments in evaluating professionalism. Med Educ 2005;39 (8):763-8.

Boenink AD. Teaching and learning reflection on medical professionalism (dissertatie). Enschede: Gildeprint Drukkerijen B.V. ; 2006.

The royal college of physicians and surgeon's of Canada's Canadian Medical Education directions for Specialists 2000 project. Skills for the new millenium: report of the societal needs working group. CanMeds 2000 Project 1996; Ottawa, Ontario, Canada. 